\title{
Le Retour au désert: 0 grotesco em Koltès
}

Le Retour au désert: The Grotesque in Koltès

\section{Renata Cazarini de Freitas}

Renata Cazarini de Freitas

Doutoranda no Programa de Pós-Graduação em Letras Clássicas da

Faculdade de Filosofia, Letras e Ciências Humanas da Universidade de São Paulo (FFLCH/USP). Professora-assistente de Língua e Literatura Latina na Universidade Federal Fluminense (UFF)

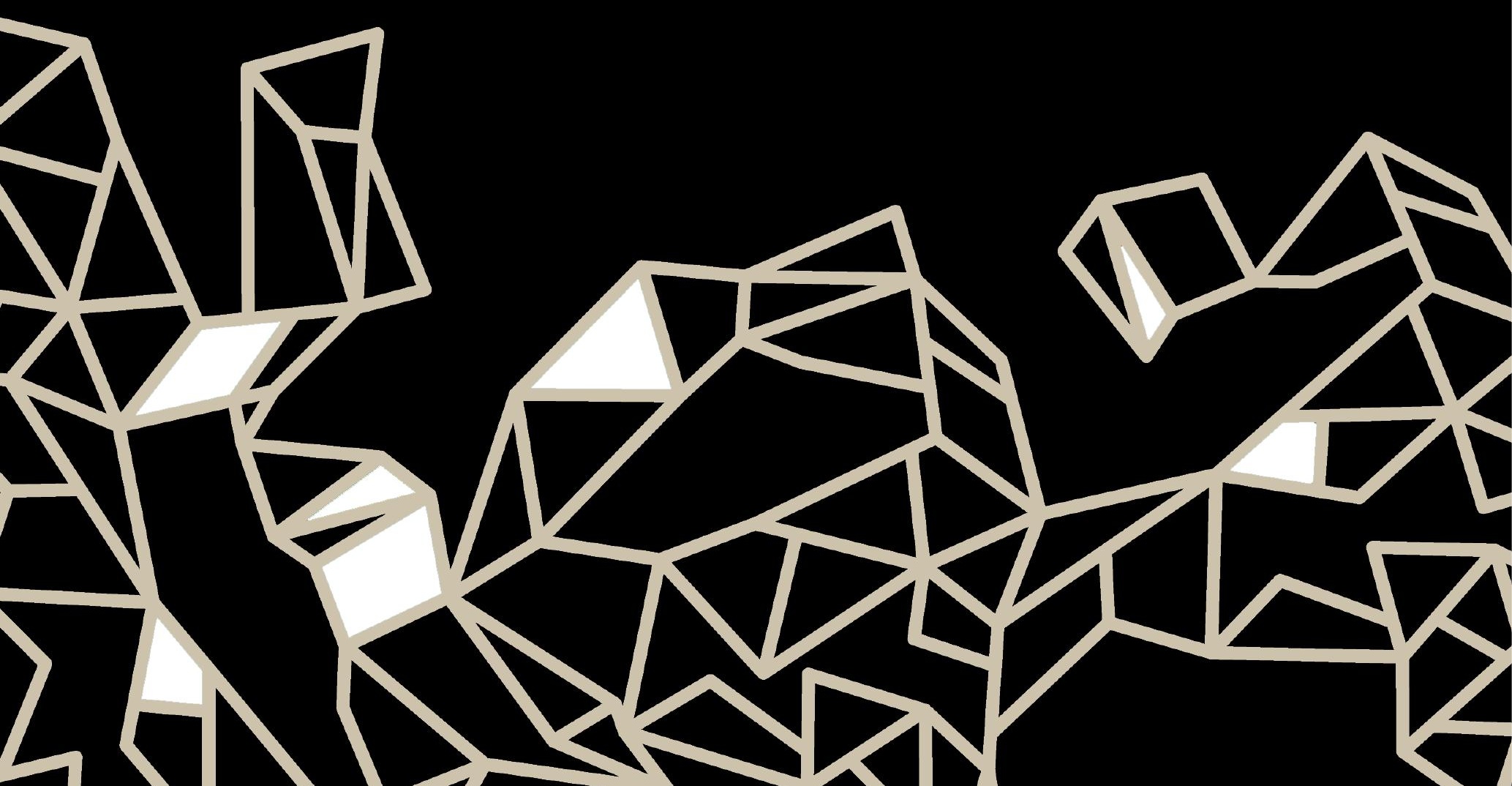




\section{Resumo}

Este artigo se propõe a demonstrar como o dramaturgo Bernard-Marie Koltès atravessou a ponte da retórica antiga para extravasar para o palco contemporâneo o tema da guerra e da falta de liberdade, retomando memórias pessoais em Le Retour au désert ( $O$ retorno ao deserto, 1988). A análise é centrada nas rubricas e na enunciação discursiva.

Palavras-chave: Retórica, Discursividade, Memória.

\section{Abstract.}

This article aims to demonstrate how the playwright Bernard-Marie Koltès crossed the bridge of ancient Rhetoric to vent to the contemporary stage the theme of war and lack of freedom, resuming personal memories in Le Retour au désert (The Return to the Desert, 1988). The analysis focuses on the didaskalia and the discursive enunciation.

Keywords: Rhetoric, Speech, Memory.

A singularidade da peça Le Retour au désert (1988) na obra de Bernard-Marie Koltès (1948-1989) está no recorte histórico, com definição bastante precisa do período que retrata: o início da década de 1960, em meio à guerra da Argélia (1954-1962), numa cidade do leste francês. Muitas declarações de Koltès revelam as relações entre a trama e suas memórias adolescentes em Metz, capital da província de Lorraine, próxima à fronteira com a Alemanha.

Esse contexto autobiográfico, longe de contaminar a leitura dramatúrgica da peça, permite uma aproximação a referentes geográficos e culturais do texto. Disso é exemplo a atribuição a algumas personagens de nomes de bairros de Metz. Assim como vale a pena saber que ela foi importante cidade na Gália dominada pelos romanos para entender a menção a Rômulo e Remo.

Nessa penúltima peça (seguida apenas de Roberto Zucco, 1988), Koltès situa sua dramaturgia na fronteira entre tragédia e comédia, pautada pela ironia - uma sátira dramática da mentalidade burguesa da França provincial no século XX. Ele joga também com as unidades clássicas de tempo e espa- 
ço, assim como introduz o fantástico e o grotesco. Pode-se até pressupor um flerte com o realismo fantástico latino-americano (Cem anos de solidão, de Gabriel García Márquez, 1967), já que o autor francês fez publicar um texto subsidiário, Cent ans d'histoire de la famille Serpenoise, em que detalha tanto os antecedentes como os fatos posteriores à trama da peça.

Também deve ser considerado o momento profissional em que foi elaborada, em paralelo à tradução de The Winter's Tale, de William Shakespeare, que aguçou em Koltès a liberalidade na composição dramática, retomando o fantasma da tragédia de vingança (revenge tragedy), afastando-se do classicismo francês, da vraisemblance, da bienséance. No entanto, a estrutura da peça é clássica, estabelecendo cinco atos em que estão distribuídas as dezoito cenas - com a provocação de situá-las temporalmente em relação às preces islâmicas cotidianas - e são explorados retoricamente os recursos tradicionais do diálogo e do monólogo.

Para demonstrar como Koltès atravessa a ponte da poética antiga para extravasar na experiência coletiva do teatro contemporâneo a experiência da sua adolescência em Metz com o outro, sendo esse o árabe, proponho a abordagem do texto a partir da teoria dos atos de fala de John Austin (19111960), refletindo a concepção de que o objeto central do teatro contemporâneo é a enunciação, em menor grau o enunciado. Considerando-se o duplo emissor, scriptor e personagem, este trabalho analisará as rubricas, que determinam as condições de exercício da fala, assim como exemplificará correlações de força nos contratos de fala.

Como observa Anne Ubersfeld (2005, p. 160), o conjunto do discurso do texto dramático é composto de ambos os subconjuntos: o discurso enunciador do scriptor e o discurso enunciado da personagem. Esta, como instância de enunciação, e o discurso teatral, como tensão entre língua e corpo, são os mediadores da ideologia investida num texto teatral.

[O] que, na leitura de textos outros (discursivos ou romanescos), é entendido apenas como um trabalho crítico sobre o texto pode, no teatro, tomar forma e, em sentido próprio, ser exibido pela encenação; tudo se passa como se a tarefa do encenador fosse precisamente mostrar "visualmente" as situações de linguagem e, por extensão, as posições discursivas. (UBERSFELD, 2005, p. 181) 
Na análise do discurso da personagem, há modalizadores - verbos, pronomes etc. - que a constituem como orador, que fazem funcionar sua retórica própria. No diálogo, evidenciam-se tentativas de estabelecer relações de força que podem estar explicitadas no enunciado somente, mas que também podem ser identificadas com base nos pressupostos que o governam.

\section{Análise das rubricas}

Título: Le Retour au désert foi a segunda, não a primeira opção de Koltès para nomear a peça, concluída em meados de 1987 e editada no ano seguinte, que originalmente ele chamara de La ville s'éveille. O autor desejava "éliminer tout ce qui pourrait passer pour de la poésie", conforme carta enviada em julho do mesmo ano a Claude Straz, amigo pessoal e do teatro, a quem pediu uma leitura prévia do texto (KOLTĖS, 2009, p. 511-2). Pouco depois, em setembro, ao seu agente na Alemanha, Stefani Hunzinger, afirmava que o novo título era o definitivo e que "l'autre a été announcé un peu à la hâte, mais il n'était que provisoire" (KOLTÈs, 2009, p. 514).

Além da radical mudança prosódica - do melódico La ville s'éveille para o áspero Le Retour au désert -, o novo título implicou também outro foco: não mais a cidade como agente da ação, mas o retorno - a ideia abstrata ganhava centralidade. $E$ isso permite ampliar a interpretação. Numa leitura literal do título, pode-se subentender a ação de deixar um local para ir a outro em que já se esteve, portanto, volta, regresso, retorno. O deslocamento se dá a partir de um ponto não identificado em direção a um determinado, o deserto, embora não delimitado: de que deserto se trata? De um deserto como espaço físico não cultivado, talvez desabitado, caracterizado pelo clima árido? Ou apenas da ideia, do conceito, de deserto?

A não delimitação autoriza uma dimensão adicional à leitura de retour, mais abstrata, a do regresso a um estado anterior, a do retorno a um estado habitual, como indica no verbete o dicionário Le Robert. Esse possível estado de deserto remete, por sua vez, ao isolamento, ao não se fazer entender, ao prêcher dans le désert: o que tematiza a linguagem, matéria cara a Koltès em toda a sua obra.

Epígrafe: A opção de exibir uma epígrafe antes do texto dramático não foi uma iniciativa do autor apenas para Le Retour au désert. Ele o fez em 
outras peças. A escolha do trecho específico de Richard III, de Shakespeare, abre caminhos ao leitor do texto impresso e propõe ao encenador ângulos de interpretação: "Porquoi les branches poussent-elles encore, alors que la racine est desséchée? Porquoi les feuilles ne dessèchent-elles pas, alors qu'elles sont privées de leur sève?". ${ }^{1}$

A partir dos dois versos pinçados do Ato II, cena 2 (fala da rainha Elizabeth, personagem não identificada na epígrafe), a tradução, quase seguramente realizada pelo próprio Koltès, evoca uma série de ideias e imagens. Depois de ter adaptado Hamlet em 1974, a partir de traduções francesas, em Le jour des meurtres dans l'historie d'Hamlet, e de ter traduzido em 1987 The Winter's Tale, Koltès considerava retomar Shakespeare - Richard III ou King Lear - em mais um trabalhoso processo de versão.

O uso do verbo dessécher traz à mente a secura e o sol desérticos - a raiz não apenas fenece, ela se resseca. $A$ referência à condição climática $e$ a associação dos humores humanos ao frio e ao calor é ideia colocada logo na abertura de Richard III, quando Ricardo refere-se ironicamente à vitória do irmão e rei Eduardo IV, que ele inveja: "Now is the winter of our discontent made glorious summer by this son of York". Essa assonância entre son (filho) e sun (sol, símbolo da casa de York) promove o primeiro jogo de palavras (pun) da peça, distintivamente marcada pela retórica da personagem-título.

Essa epígrafe remete, portanto, ao Koltès que virá ao longo da peça, tanto no tema como na forma. Uma moldura que se delineia na epígrafe: jogos de palavras, a ambivalência concreto-abstrato, fundamentos que fenecem (racine ou Racine?) enquanto o ciclo da vida continua, a linguagem como exercício de poder, o poder como objeto da disputa entre irmãos.

Espaço/tempo: $\mathrm{O}$ autor contesta em entrevistas que tenha escrito uma peça política ou mesmo sobre a Guerra da Argélia. Para ele, trata-se de um texto sobre um território bem conhecido - a província francesa e sua desconcertante burguesia: "J'ai voulu mélanger les deux, faire rire, et on même temps, inquiéter"

1 Em inglês: "Why grow the branches now the root is wither'd? Why wither not the leaves that want their sap?". Em português: "Por que os galhos continuam crescendo, quando sua raiz secou? Por que as folhas não secam, quando privadas de sua seiva?" (KOLTĖS, 2010, p. 135, tradução de Angela Leite Lopes). 
(UBERSFELD, 2001, p. 66). Para Ubersfeld, "tout le travail de la construction est d'articuler la famille et l'histoire" (UBERSFELD, 2001, p. 107).

Assim, o pano de fundo dessa sátira de costumes pontuada pela violência inclui uma ação clandestina da Organisation Armée Secrete (OAS), que combatia a luta da Argélia pela independência, e remonta ainda à Segunda Guerra Mundial (1939-1945), lembrando a retaliação a quase vinte mil mulheres denunciadas como colaboracionistas e levadas a desfilar com a cabeça raspada nas ruas, sob as vaias de populares, após a França ter se libertado em 1944 da ocupação alemã.

O intervalo em que se desdobra a peça não é preciso, mas o desfecho pressupõe ao menos nove meses, já que a personagem Fátima engravida e da à luz filhos gêmeos d'O Grande Paraquedista Preto. No texto subsidiário Cent ans d'histoire..., o dramaturgo especifica que o retorno de Mathilde Serpenoise à cidade ocorre em novembro de 1960, e que ela e o irmão Adrien partem de lá em 1961, o que acontece após o parto. Essa ruptura da clássica unidade de tempo é "une provocation humoristique", segundo Ubersfeld (2001, p. 119), que não prejudica o ritmo.

Personagens: Das quatorze personagens de Le Retour au désert, os homens somam praticamente o dobro das mulheres. Ainda assim, o efeito é de um texto dramático muito marcado pelo discurso feminino. A denominação das personagens pode ser tomada como indício da relevância que Koltès atribui à mulher no embate entre gêneros que tem lugar na peça. Apenas duas personagens, ambas femininas, recebem nome e sobrenome: Mathilde Serpenoise e a falecida Marie Rozérieulles. Há no texto dramático vários indícios do espeIhamento entre elas, mas vale mencionar que no Cent ans d'histoire... o autor coloca Mathilde e Marie nascendo à mesma hora no mesmo dia de 1908, em casas nos lados opostos da mesma rua. Marie é o fantasma na peça.

O Grande Paraquedista Preto é a única personagem à qual não se atribui nome ou qualquer relação. Ele se identifica por sua função. A cor da personagem é crucial no desfecho da fábula. Encenação na Alemanha não comprometida com esse quesito foi condenada publicamente pelo autor (KOLTÈS, 2006, p. 141).

Uma pesquisa na web revela que Koltès transferiu a toponímia de Metz $e$ região para as personagens, vinculando a peça a uma memória espaço-temporal particular, como reconheceu ao afirmar que a escreveu aos 40 anos, 
pronto a retomar lembranças distantes e a falar de uma cidade provinciana: "C'est la mienne, bien sûr" (KOLTÈS, 2006, p. 137).

Assim, o sobrenome Serpenoise é também o nome da porte Serpenoise, em Metz, construída sobre as ruínas da porte de Scarponne, na antiga estrada romana via Scarponensis, que ligava Divodurum Mediomatricorum (Metz) a Verdun, passando pela pequena Rozérieulles. Além disso, outras personagens são nomes de bairros em Metz - Plantières-Queuleu, Borny, Sablon. E ainda, curiosamente, uma etimologia um tanto fantasiosa, mas corrente, para Queuleu é "o rabo do lobo" (queue du loup), numa possível alusão à loba mitológica que alimentou Rômulo e Remo, nomes que surgem no fim do texto dramático como filhos de Fatima e d'O Grande Paraquedista Preto.

Bilinguismo: Logo abaixo da relação das personagens na edição da peça, uma nota informa que traduções de falas em árabe encontram-se no fim do volume. O bilinguismo tende a ser um dificultador do diálogo, porém é também indício de que é dada voz ao estrangeiro, ao diferente. Embora duas personagens tenham nomes árabes, Aziz e Saïfi, surpreende que a língua estrangeira se faça ouvir logo na primeira cena da peça francesa, causando de imediato uma "situação de linguagem," não pela incomunicabilidade, mas justamente pelo inesperado da posição discursiva de Mathilde equivalente a Aziz em relação à língua árabe. As demais falas em árabe estão concentradas no Ato V, cena 15, entre Aziz e Saïfi.

Locais cênicos: É a casa dos Serpenoise o local cênico predominante na peça. É ao jardim, no entanto, que se faz referência constante e onde acontece o inusitado aparecimento do fantasma de Marie, o que o eleva à dimensão do fantástico. A casa mesma é referida por algumas personagens como tendo sua própria personalidade, numa quase antropomorfização. Os muros altos do jardim são uma barreira não apenas concreta a ser transposta para se acessar o mundo lá fora, mas também metafórica, que isola e protege a família Serpenoise da guerra. Ainda assim, segundo Ubersfeld (2001, p. 112), "ce cocon est envahi"' por Mathilde e pel'O Grande Paraquedista Preto. É capital a existência de um segundo local cênico, introduzido no Ato V, cena 15, rompendo a clássica unidade de lugar. O bar Saïfi, simbolizando os

2 "Este casulo é invadido" (tradução minha). 
bares árabes da memória de Koltès, ${ }^{3}$ é apresentado para ser, em seguida, destruído por uma explosão que apenas se ouve ao longe. Segundo Ubersfeld (2001, p. 115), essa ruptura é necessária para expor a violência política.

Entradas e saídas: A mais significativa rubrica quanto a entradas e saídas ocorre no fim do monólogo de Edouard, filho de Mathilde, Ato V, cena 17, quando o autor determina: "Ele toma impulso, pula e desaparece no espaço" (KOLTÈS, 2010, p. 218). Essa rubrica estabelece o caráter fantástico da cena e fantasioso da personagem.

\section{Análise das falas}

O diálogo em Le Retour au désert é construído como exibição de excelência retórica, condizente com as situações de fala em que personagens buscam uma posição de força na troca verbal. A habilidade oratória surge, então, como instrumento de poder, cetro e coroa de quem manda no pequeno reino - seja na casa dos Serpenoise, seja na cidade provinciana.

É do interesse dos antagonistas, Mathilde e seu irmão Adrien, que o diálogo se estabeleça para que possam exibir sua destreza, mesmo que dessa conversa nada resulte de prático. Como diz Maame Queuleu no Ato II, cena 6: "Pois vocês só brigam com palavras, palavras, palavras inúteis que machucam todo mundo, menos vocês" (KOLTÈS, 2010, p. 168).

Os diálogos têm, assim, uma artificialidade intencional, um maneirismo que remonta à dramaturgia antiga, como a de Sêneca, dramaturgo latino do século I d.C., preservada em muitas de suas características no teatro elisabetano de Shakespeare. Também os monólogos são enunciados deslocados da progressão dramática, peças de oratória.

A prosódia é marcada por certas figuras de linguagem da retórica antiga, como a repetição de estruturas frasais (repetitio), o uso sequencial de

3 "En province, tout cela se passait quand même d'une manière étrange; l'Algérie semblait ne pas exister et pourtant les cafés explosaient et on jetait les Arabes dans les fleuves. Il y avait cette violence-là, à laquelle un enfant est sensible et à laquelle il ne comprend rien. Entre douze et seize ans, les impressions sont décisives, je crois que c'est là que tout se décide" (KOLTĖS, 2006b, p. 115). Minha tradução: "Na província, tudo isso se dava de uma forma estranha; a Argélia parecia não existir e, no entanto, os cafés explodiam e se jogava os árabes nos rios. Havia essa violência, à qual uma criança é sensível e da qual ela não entende nada. Entre doze e dezesseis anos, as impressões são cruciais, penso que é quando tudo se define". 
perguntas (interrogatio), a articulação de elementos entrecortando o discurso (articulus) e a retomada de palavras pelo antagonista como gancho para prosseguir o diálogo, característica da tensa troca esticomitíaca.

Numa avaliação do primeiro diálogo entre os irmãos protagonistas, verifica-se uma altercação (altercatio), procedimento retórico consagrado no antigo debate judicial romano, em que Adrien, que detém o contrato de fala inicial, propõe número maior de tópicos, que são desafiados por Mathilde, embora alguns ela prefira ignorar.

A posição de força de Adrien evoca um dominus, um pater familias romano, como ele mesmo explicita ao afirmar no diálogo inicial com Mathilde no Ato I, cena 2: "Essa casa é uma casa de homens, e as mulheres que passam por aqui serão aqui sempre apenas convidadas e esquecidas" (KOLTÈS, 2010, p. 140). Essa confrontação dos gêneros - homens versus mulheres - é um tópico introduzido por ele nos embates com a irmã, assim como o da estadia dela na Argélia, o da escolha imprópria que ela teria feito na partilha. Ela os evita a princípio, mas acaba por aceitá-los. Contudo, a frase final em Le Retour au désert é de Mathilde, que propõe o último contrato de fala, convencendo o irmão a partir com ela da cidade.

Os tópicos conversacionais são facilmente reconhecíveis ao longo do texto: o tempo, a ausência, a memória, a vingança, a propriedade, a partilha, o segredo, o medo, a guerra, a família. O tema latente, subentendido, mas não explicitado, é o da liberdade. Todas as personagens estão submetidas a grilhões - morais, sociais, políticos, econômicos - dos quais não conseguem se desvencilhar. A saída derradeira dessa armadilha é a fuga para o espaço, tal como Edouard a concebe em palavras, e que se realiza somente na encenação da peça.

Na estrutura profunda do texto dramático é possível identificar o tema do duplo, que vem à superfície como "o estrangeiro". Essa alteridade subterrânea em Le Retour au désert é muito mais do que o árabe ou o não francês. É o outro que é o igual: é Mathieu, caricatura de Adrien; Adrien que é a irmã Mathilde de calças; Mathilde que é o inverso de Marie; Marie que é a irmã Marthe meIhorada; Mathieu querendo ser Edouard; Edouard que desaparece como Aziz; Aziz que era o duplo de Maame Queuleu; Maame Queuleu, o único suporte de Marthe; Marie que só existe para Fátima; Fátima que dá à luz gêmeos. 
O Grande Paraquedista Preto, que se compara a um "floquinho de neve" caído do céu em pleno verão para trazer segurança, tendo invadido o jardim da mansão dos Serpenoise, é mais um recurso do fantástico, mas colado ao cômico - enunciação jocosa para temática grave, tão grotesca como a aparição de Marie para denunciar a arrogância burguesa.

O paraquedista chama Adrien de "burguês" e é chamado de "militar" pelo dono da casa. O diálogo é tenso, no tempo presente, até que a cena praticamente se encerra com um monólogo do paraquedista centrado na mudança de referenciais geográficos no pós-colonialismo. $O$ tempo verbal muda para o pretérito imperfeito, acompanhando a manifestação de "saudade" de uma época em que "cada um tinha o seu lugar." A denúncia do militar é contra o desmoronamento do sistema identitário, que se assenta em cada um ter seu lugar, sua função, seu nome, sua casa, sua cidade, sua nação. É uma fala de extrema poeticidade, com repertório lexical que inclui "amor", "nostalgia", "saudade", "fronteiras", "morte" e imagens como lâmpadas a óleo, barcos a vela, cadeira de balanço. Também esse texto é construído com figuras como a repetitio.

\section{Conclusões}

A contemporaneidade de Koltès em Le Retour au désert talvez possa ser posta em causa. A peça é centrada na enunciação, na força retórica das personagens que disputam cada qual seu lugar, fazendo o melhor uso que podem da linguagem. Não é demais afirmar que se trata de um texto dramático decalcado da tradição oratória e da mitologia antigas. O dramaturgo preservou a fábula, embora numa estrutura fragmentária, dividida nos cinco atos clássicos. A justaposição de cenas, que se enxerga como característica do teatro contemporâneo, remonta ao drama antigo, como as tragédias de Sêneca em que o encadeamento da ação é interrompido por monólogos e seções corais muitas vezes de temática apenas adjacente à trama. Mecanismos retóricos preceituados na oratória judiciária e deliberativa latina trazem certo maneirismo aos diálogos e monólogos de Koltès.

Essas características foram assimiladas pelo teatro elisabetano e, muito provavelmente sob a influência de Shakespeare, o autor as privilegiou nesse texto dramático. Mas ele também tomou emprestado ao bardo o à vontade 
com a mistura de gêneros, não se furtando ao "grotesco", nos termos de Victor Hugo. Matéria nobre - a guerra, o exílio, a morte - convivendo com o risível. Como Mathilde ironiza as aparições de Marie no Ato V, cena 16: "As pessoas lá aparecem ainda em nossa época? Era bom para os camponeses histéricos dos campos de outrora. Mas hoje, isso é grotesco. Nem a Santa Virgem ousaria" (KOLTÈS, 2010, p. 211). Koltès ousou, porém acentuando que a peça é "une bizarrerie" (UBERSFELD, 2001, p. 63).

Menos bizarra, possivelmente, se na estrutura profunda do texto se puder resgatar o interesse do autor pela construção identitária ao longo da história e como Metz, ex-colônia do império romano, foi por ela condicionada. Na peça, é feita alusão ao mito da fundação de Roma mais de uma vez. Os paralelismos entre os Serpenoise e o mito são ainda mais numerosos do que a referência à loba e a Rômulo e Remo.

É crucial no mito da fundação de Roma a narrativa da transposição das muralhas iniciadas por Rômulo no monte Palatino pelo irmão Remo, numa atitude de zombaria que resultou em sua morte. "Sic deinde, quicumque alius transiliet moenia mea" [Assim morrerá de agora em diante qualquer outro que ultrapassar as minhas muralhas] (TITO LÍVIO, 2008, p. 49). Então, Rômulo tornou-se o primeiro rei de Roma, sem divisão de poder. Em Le Retour au désert, os altos muros que protegiam o território sagrado dos Serpenoise foram transpostos pel'O Grande Paraquedista Preto, um deus da guerra como Marte, a quem é atribuída a paternidade de Rômulo e Remo depois de ter violado a vestal Reia Sílvia.

Tal como o rei Amúlio na mitologia de Roma havia afastado do poder o herdeiro mais velho Númitor, Adrien também exilara Mathilde. A filha dela, Fátima, seria isolada por insanidade assim como Reia Sílvia, filha de Númitor, foi apartada como vestal. $O$ inesperado, o nascimento dos gêmeos, destituiu por fim Adrien de seu pequeno reino. O próximo entrechoque de irmãos pelo poder já é antecipado por Mathilde, que deixa para trás a Roma do nordeste francês numa situação de fronteiras indefinidas e identidades confusas.

\section{Referências bibliográficas}

KOLTÈS, B.-M. Combate de negro e de cães; O retorno ao deserto; Tabataba. Tradução Angela Leite Lopes. São Paulo: Aliança Francesa; Instituto Totem Cultural; Imesp, 2010. 
Lettres. Paris: Les Éditions de Minuit, 2009.

. Une part de ma vie: Entretiens (1983-1989). Paris: Les Éditions de Minuit, 2006.

TITO LÍVIO. História de Roma, Livro I: A Monarquia. Tradução Mônica Costa Vitorino. Belo Horizonte: Crisálida, 2008.

UBERSFELD, A. Para ler o teatro. Trad. José Simões (Coord.) São Paulo: Perspectiva, 2005.

Bernard-Marie Koltès. Arles: Actes Sud - Papiers, 2001.

Recebido em 08/09/2016

Aprovado em 04/11/2016

Publicado em 21/12/2016 